\title{
Is Active Learning Accessible? Exploring the Process of Providing Accommodations to Students with Disabilities
}

Logan E. Gin, ${ }^{\dagger}$ Frank A. Guerrero, ${ }^{\dagger}$ Katelyn M. Cooper, ${ }^{\ddagger \S}$ and Sara E. Brownell ${ }^{\S *}$ 'Biology Education Research Lab, "Research for Inclusive STEM Education Center, School of Life Sciences, Arizona State University, Tempe, AZ 85281

\begin{abstract}
On average, active learning improves student achievement in college science courses, yet may present challenges for students with disabilities. In this essay, we review the history of accommodating students with disabilities in higher education, highlight how active learning may not always be inclusive of college science students with disabilities, and articulate three questions that could guide research as the science community strives to create more inclusive environments for undergraduates with disabilities: 1) To what extent do stakeholders (disability resource center [DRC] directors, instructors, and students) perceive that students with disabilities encounter challenges in active learning? 2) What accommodations, if any, do stakeholders perceive are being provided for students with disabilities in active learning? and 3) What steps can stakeholders take to enhance the experiences of students with disabilities in active learning? To provide an example of how data can be collected to begin to answer these questions, we interviewed 37 DRC directors and reported what challenges they perceive that students with disabilities experience in active learning and the extent to which accommodations are used to alleviate challenges. We conclude the essay with a suite of recommendations to create more inclusive active-learning college science classes for students with disabilities.
\end{abstract}

\section{INTRODUCTION}

National recommendations have encouraged college science instructors to shift their teaching from traditional lecture to active learning (American Association for the Advancement of Science, 2011). In active-learning classes, students engage in constructing their knowledge as opposed to passively listening to an instructor for an entire class session. Active-learning practices, on average, have been shown to have a positive impact on student learning (Freeman et al., 2014), and there is some evidence that active learning may decrease achievement gaps between students in minority and majority groups (Haak et al., 2011; Eddy and Hogan, 2014; Ballen et al., 2017; Theobald et al., 2020). As such, active learning may be assumed to be more equitable than traditional lecture, and it has even been considered an inclusive teaching practice (Dewsbury and Brame, 2019).

However, active learning significantly changes the classroom structure in ways that could create challenges for some students, potentially introducing inequities that are not present in traditional lecture courses. Previous research has indicated that how active-learning practices are implemented, particularly with regard to student participation and social interactions, can create challenges for groups of students who are typically underserved or underrepresented in science, including women, students with anxiety, and LGBTQ+ students (Eddy et al., 2015; Cooper and Brownell, 2016; Cooper et al., 2018b; England et al., 2017, 2019; Ballen et al., 2019; Downing et al., 2020). We propose that students with disabilities may be an additional underrepresented
Cynthia Brame, Monitoring Editor

Submitted Mar 16, 2020; Revised Jul 9, 2020; Accepted Jul 23, 2020

CBE Life Sci Educ December 1, 2020 19:es12 DOI:10.1187/cbe.20-03-0049

sThese authors contributed equally.

*Address correspondence to: Sara E. Brownell (sara.brownell@asu.edu).

(c) 2020 L. E. Gin et al. CBE-Life Sciences

Education $\odot 2020$ The American Society for Cell Biology. This article is distributed by The American Society for Cell Biology under license from the author(s). It is available to the public under an Attribution-Noncommercial-Share Alike 3.0 Unported Creative Commons License (http://creativecommons.org/licenses/ by-nc-sa/3.0).

"ASCB®" and "The American Society for Cell Biology $\circledR^{\prime \prime}$ are registered trademarks of The American Society for Cell Biology. 
group in science that faces unique challenges in active learning (Moon et al., 2012; Gonzales, 2016; Hall, 2017; Braun et al., 2018). We assert that, while the transformation of college science courses into active-learning courses is critical to enhance student learning overall, it has the potential to create additional barriers and challenges for students with disabilities. While certain institutional programs are mandated to support students with disabilities, such as disability resource centers (DRCs), the extent to which these programs have evolved to accommodate possible challenges that active learning presents for students with disabilities is unclear.

In this essay, we review the history of accommodating students with disabilities in higher education and highlight how active learning may not be an inclusive teaching approach for college students with disabilities without modifications to the current accommodations and support. We present three guiding questions to consider as we strive toward creating more inclusive college science active-learning environments for students with disabilities. We argue that these questions need to be addressed from the perspectives of students with disabilities, active-learning instructors, and directors of DRCs. To demonstrate that these guiding questions could be useful in developing more inclusive undergraduate science education, we interviewed directors of DRCs from 37 institutions of higher education across the United States about how they are accommodating students with disabilities in active-learning science classrooms and the challenges associated with accommodating students in active-learning environments. Finally, we present a suite of recommendations for instructors and DRC staff who aim to create more inclusive active-learning college science classes for students with disabilities.

\section{WHO ARE STUDENTS WITH DISABILITIES?}

The social model of disability, which emerged during the disabilities rights movement of the 1970s and 1980s, argues that disability is a social construct; an individual may have a functional limitation or physical, mental, or sensory impairment, but what makes that individual have a disability is that opportunities are taken away due to the attitudes and structures of society (Oliver, 1996, 2013; Shakespeare, 2006). For example, an individual with muscular dystrophy (impairment) may be unable to enter a building with a wheelchair if the building does not have a ramp or accessible entrance (disability).

What is considered proper discourse regarding disabilities has changed in the last few decades. Describing someone as "handicapped" or "differently abled" is outdated and can be offensive to some people; this language has predominately been replaced with person-first language (e.g., "student with a disability"). Person-first language ${ }^{1}$ places the emphasis on the individual, not the disability, which implies that the individual is foremost a person who happens to

\footnotetext{
${ }^{1}$ We acknowledge that there has been some criticism of the use of person-first language, particularly from the autistic community (e.g., Kenny et al., 2016), Deaf community (e.g., Lum, 2010), and blind community (e.g., Vaughan, 2009). While we respect and recognize these concerns, we have chosen to use person-first language (e.g., student with a disability) in this essay, because we feel as though it is most generalizable to all students with disabilities.
}

have a disability (National Center on Disability and Journalism, 2018). Notably, the American Psychological Association considers person-first language a general principle of biasfree language for talking about disability with inclusivity and respect (APA, 2020). We have chosen to use person-first language to describe students with disabilities in this essay, because it emphasizes that the disability does not define the person.

There are various definitions of "disability" used in different contexts. The Americans with Disabilities Act (ADA) of 1990 defines disability as "a physical or mental impairment that substantially limits one or more major life activities, a record of such impairment, or being regarded as having such an impairment" (ADA, 1990, 2008). The U.S. Department of Education's National Center for Education Statistics operationalizes disability to include those who report any type of disability related to "blindness, deafness, severe vision or hearing impairment, substantial limitation of mobility, or any other physical, mental, or emotional condition that lasted six months or more" (National Center for Education Statistics, 2015). For the purposes of this essay, we draw from both of these definitions and focus on disabilities that would typically be serviced by university DRCs. These include, but are not limited to, learning disabilities (e.g., autism, dyslexia), physical disabilities (e.g., cerebral palsy, spina bifida), chronic health conditions (e.g., cancer, diabetes), vision loss, hearing loss, and mental health and psychological disabilities (e.g., anxiety, depression).

\section{HISTORY OF STUDENT ACCOMMODATIONS IN HIGHER EDUCATION}

Students with disabilities have been recognized as an at-risk population in higher education and have been legally protected in the United States since 1973. Section 504 of the Rehabilitation Act of 1973 (hereafter Section 504) and the Americans with Disabilities Act of 1990 (ADA, 1990) prohibit discrimination on the basis of disability in programs or activities that receive federal financial assistance (Eckes and Ochoa, 2005; Madaus, 2005). Specifically, Section 504 requires public and private postsecondary institutions that receive federal aid or funding (e.g., National Science Foundation [NSF], National Institutes of Health [NIH], Free Application for Federal Student Aid [FASFA]) to consider applications from qualified students with disabilities. It also requires colleges and universities to make modifications to courses through the use of auxiliary aids and services (e.g., interpreters, note-takers, transcriptionists) for students with disabilities (Feldblum, 1996; Madaus, 2011). Similarly, the ADA requires that colleges and universities make course modifications to accommodate students with disabilities, as long as such modifications do not fundamentally alter academic programs in such a way that they change the nature of the program being offered (ADA, 1990; Meeks and Jain, 2015).

The passage of this legislation to ensure the rights of students with disabilities has contributed to the increase in the number of students with disabilities in higher education, and in turn, the number of programs designed to specifically serve students with disabilities has also grown (Madaus, 1996). While these disability service programs can vary widely, the most common version is a disability resource 
center, ${ }^{2}$ which describes an office on a university campus that provides academic and social services for students with disabilities and diagnosed medical conditions (Section 504, 1973; ADA, 1990). On many campuses, DRCs are the units responsible for providing college students with academic accommodations in their courses and keeping the institution in compliance with the federal mandates.

\section{CHALLENGES IN ACCOMMODATING STUDENTS WITH DISABILITIES IN HIGHER EDUCATION}

Despite the legal requirements for institutions to support students with disabilities and the increased number of DRCs serving students, there are a myriad of challenges that hinder students with disabilities from accessing the appropriate accommodations in the college classroom (West, 1993; Dowrick et al., 2005; Marshak et al., 2010). Studies have demonstrated that students with disabilities sometimes are unaware of the presence of a DRC on campus or are uncertain of the range of services that DRCs provide (Dowrick et al., 2005; Marshak et al., 2010). Additionally, even if a student knows that their institution's DRC exists, they may have trouble using DRC services because of the amount of time and effort it can take to access such services. Students with disabilities need to be their own advocates in college, because it is solely their responsibility to recognize when they need an accommodation (Brinkerhoff et al., 2002; Eckes and Ochoa, 2005). This is in stark contrast to many students' experiences in high school, where a student's family as well as school officials and teachers are primarily responsible for recognizing a student's disability and taking action to provide appropriate accommodations (Janiga and Costenbader, 2002; Smith et al., 2002; Madaus, 2005; Hadley, 2007). Further, there is often a stigma associated with having a disability; individuals with disabilities are often discriminated against in society, and students may be reluctant to disclose their disabilities in the context of college (Fine and Asch, 1988; Trammell, 2009; Meredith, 2014). Students may fear being singled out by an instructor for their disabilities, which may encourage them to conceal their disabilities, if possible (Ruban et al., 2003; Getzel and Thoma, 2008; Marshak et al., 2010). Finally, if students perceive DRC accommodations to be ineffective or if they have previously had a negative experience with the DRC, they may avoid using their services in the future; a survey of students registered with disability services at community and technical colleges found that students are most likely to use accommodations when they view them as effective for improving their independence (Kurth and Mellard, 2006). Given that students must know to advocate for themselves, learn about and seek services from their institutions' DRCs, and identify useful accommodations, it is unsurprising that navigating the accommodations process can be physically, mentally, and emotionally taxing for students with disabilities (Hong, 2015).

In addition to engaging directly with the DRC, students with disabilities often need to discuss their disabilities and their

\footnotetext{
${ }^{2}$ The term Disability Resource Center (DRC) is the general term to describe offices on college campuses that support students with disabilities. We acknowledge that some institutions have other names to describe these offices, such as disability support services, accessibility services, student access centers, and accommodation resource offices. For the purpose of this essay, we have chosen to use the term "DRC," because it is commonly used to describe these types of offices on many college campuses.
}

requested accommodations with their instructors. These interactions can be negative, and it has been reported that instructors can have lower academic expectations for students with disabilities compared with students who do not have disabilities (Marshak et al., 2010; Hong, 2015). The most commonly cited issue by students with disabilities in the Florida College System was the attitudes of faculty and staff who were not familiar with disability concerns (Florida College System, 2009). Instructors have also reported challenges in working with and accommodating students with disabilities in their courses; challenges were most likely to be cited by instructors with less teaching experience and instructors with less experience working with students with disabilities (Johnson, 2006). In an interview study of five faculty members who have taught students with disabilities at their institutions, the instructors discussed a lack of professional support and guidance for how to work with students with disabilities, procedural issues with accommodating students (e.g., not being informed of the nature of a student's particular disability, yet wanting to maintain student confidentiality), and challenges with specific classroom contexts and teaching practices, such as accommodating the needs of students with disabilities in a large course with limited class time (Love et al., 2014). There are no requirements for college instructors to possess the knowledge or skill sets to provide instructional accommodations for students with disabilities (Eckes and Ochoa, 2005; Rule et al., 2009), which often means that instructors are ill-equipped to handle these situations.

\section{STUDENTS WITH DISABILITIES ARE HIGHLY UNDERREPRESENTED IN SCIENCE AND MAY FACE UNIQUE CHALLENGES}

Individuals with disabilities are highly underrepresented in postsecondary science education. The American Community Survey estimated the percent of people with disabilities in the U.S. population in 2016 to be $12.8 \%$ (Erickson et al., 2017). However, individuals with disabilities make up only about $5 \%$ of students enrolled in U.S. undergraduate science, technology, engineering, and math (STEM) education (National Science Foundation, 2016).

Research conducted on the experiences of science students with disabilities in higher education has been limited, although a few studies provide insight into the challenges, issues, and barriers that college science students with disabilities may face. We suspect that challenges might contribute to the underrepresentation of students with disabilities in science. For example, science disciplines may be particularly unwilling to accommodate students with disabilities; one study showed that, regardless of the type of postsecondary institution (e.g., research-intensive, master's granting), STEM majors with disabilities received fewer accommodations than non-STEM majors with disabilities (Lee, 2011). Additionally, students with disabilities may interact with science instructors who doubt their ability to succeed and may experience a lack of adequate accommodations for their science course work (Dunn et al., 2012). There are documented academic performance differences between undergraduates studying science with disabilities and those without disabilities, likely because of the unique barriers that science students with disabilities face regarding securing proper accommodations. For example, in a study of students at a single institution, students with disabilities earned lower course 
grades on average in introductory chemistry compared with students without disabilities, despite their comparable course work in high school, SAT/ACT scores, and their ability to meet the same university admissions criteria (Street et al., 2012). In addition, a focus group study of 20 college students with disabilities found that students in science have difficulties in evaluative situations, such as lab course work, when they feel like they are being judged based on their disabilities (Jenson et al., 2011). In sum, although there are only a few studies on students with disabilities in college science, the extant research suggests that science may present specific challenges for students with disabilities.

\section{ARE ACTIVE-LEARNING SCIENCE COURSES INCLUSIVE OF STUDENTS WITH DISABILITIES?}

"Active learning" is an umbrella term used to describe a range of instructional practices that increase students' engagement in the process of learning (Bonwell and Eison, 1991; Prince, 2004; Freeman et al., 2014). Often, researchers and instructors use the term "active learning" in contrast to lecture-based instruction, in which students passively absorb information by listening to an instructor for an entire class period. There are many different ways that active learning can be implemented, including asking students to answer questions in response to the instructor, either one-on-one or in front of the whole class (e.g., cold call, random call); having students interact to solve problems (e.g., pair discussions, group work); and using technology (e.g., personal response devices, watching videos for homework in preparation for class). For the purpose of this essay, we define active learning as any instruction that is not lecturing for the full class period.

Active learning has been championed as an effective teaching practice that, on average, results in students learning more and failing less in college science courses (Freeman et al., 2014). However, active learning has also been shown to present challenges for some groups of students (Eddy and Hogan, 2014; Eddy et al., 2015; Eddy and Brownell, 2016; Cooper and Brownell, 2016; Cooper et al., 2018b; England et al., 2017, 2019; Downing et al., 2020). It is currently unknown to what extent active learning presents challenges to students with disabilities, although we hypothesize that it does. Further, it is unknown to what extent DRCs and instructors are adapting to accommodate students with disabilities in active-learning classrooms.

To move toward a more inclusive scientific community for undergraduates with disabilities, we present three guiding questions:

1. To what extent do key stakeholders (DRC directors, instructors, and students) perceive that students with disabilities encounter challenges in active-learning science courses?

2. What accommodations, if any, do key stakeholders perceive are currently being provided for students with disabilities in active-learning science courses?

3. What steps can key stakeholders take to enhance the experiences of students with disabilities in active-learning science courses?

By working to answer these questions from the three distinct perspectives (DRC directors, instructors, and students) and triangulating the data, we argue that the science community will gain a deeper understanding of the challenges that undergraduates with disabilities face in active-learning classes and the resources that are and are not available to them. It is imperative that we include the opinions of a diversity of students with disabilities who experience challenges in active learning firsthand, because their unique experiences need to be documented. However, students may not be aware of policies that are set in place by DRCs, how DRCs interact with instructors, or instructor needs that may conflict with certain accommodations. Thus, it will also be important to consider the perspectives of college science instructors who will likely provide knowledge about how accommodations can be successfully integrated into active-learning classrooms and the challenges that they face in interacting with the DRCs and students with disabilities. Finally, DRCs provide accommodations to students at scale and can speak to general trends that occur for hundreds of students over multiple years. While there are other stakeholders who we may want to consider (e.g., families of students with disabilities, university administrators), we argue that DRCs, instructors, and students with disabilities have the most experience with these issues, and their perspectives are the most relevant.

\section{FURTHERING OUR UNDERSTANDING OF THE RELATIONSHIP BETWEEN STUDENTS WITH DISABILITIES AND ACTIVE LEARNING}

The intention of this essay is twofold: to bring attention to the importance of considering the experiences of students with disabilities in active-learning courses and to demonstrate how these guiding questions could provide a foundation for helping the science education research community understand how to create inclusive active-learning classrooms for students with disabilities. We present data collected from one of the stakeholders-DRC directors-to begin to address these questions. We decided to start with DRC directors as opposed to students, because DRC directors have interacted with hundreds to thousands of students with disabilities and have a broad sense for challenges that have repeatedly arisen.

Using these guiding questions, we interviewed 37 directors of university DRCs across the United States. Specifically, we attempted to recruit directors from all large-enrollment institutions ( $>10,000$ students) based on the Carnegie Classification of Institutions of Higher Education $(n=302)$. We intentionally targeted large-enrollment institutions because these institutions typically serve a large number of students and often have a specific office on campus for students with disabilities (Madaus, 1996). Of the 302 large-enrollment institutions, we were able to find the contact information for the directors of 288 (95\%) DRCs and sent them a personalized email in Fall 2019 requesting to interview them about their accommodations for college students with disabilities. We contacted directors a second time via follow-up email if they did not respond to our initial email. Of the 288 directors we contacted, 234 (81\%) directors did not respond to either email, and 20 (7\%) directors declined to participate in an interview. We hypothesize that some DRC directors chose not to participate in the interview due to scheduling concerns with the end of the semester (e.g., final exam proctoring) or perhaps because there was no monetary incentive to participate. In total, DRC directors from 37 (13\%) institutions agreed to participate in an interview. The DRC directors we interviewed represent 17 R1 (very high research activity) institutions, 13 R2 (high research activity) institutions, six master's-granting institutions, and one bachelor's-granting institution. Seven were 
institutions located in the Northeast, seven in the South, 14 in the Midwest, and nine in the West. Three institutions were private and 34 institutions were public. A full list of anonymized institutions whose DRC directors participated in an interview is listed in the Supplemental Material and includes the type of institution, the location, and whether it is public or private.

We conducted semistructured interviews with each of the DRC directors, exploring their familiarity with active learning, the processes for providing academic accommodations for students with disabilities in active-learning science courses, and their perceptions of the challenges associated with providing accommodations for students with disabilities in active-learning science classes (see the Supplemental Material for a copy of the interview script). Interviews were audio-recorded and transcribed for analysis. We used inductive coding to identify themes from the interviews (e.g., ways in which DRCs accommodate students with disabilities in active-learning classrooms) and deductive coding to quantify director-reported knowledge or actions regarding a particular topic (e.g., the number of DRC directors who are familiar with the term "active learning"; Creswell, 1994; Thomas, 2003). Two authors (L.E.G. and F.G.) independently reviewed a different set of 10 interviews and took detailed analytical notes to identify initial themes (Birks and Mills, 2015). The two authors then came together to discuss themes and developed a codebook describing each theme. Eight interviews (22\%) were independently coded by both authors using the finalized codebook. The researchers then compared their codes, and their Cohen's $\kappa$ interrater score for these eight interviews was at an acceptable level $(\kappa=0.89$; Landis and Koch, 1977). One researcher (F.G.) then coded the remaining 29 interviews. A copy of the coding rubric can be found in the Supplemental Material.

\section{To What Extent Do DRC Directors Perceive That Students with Disabilities Encounter Challenges in Active-Learning Science Classrooms?}

For DRC directors, the first step of considering that active learning may affect students with disabilities in science is recognizing that instructors use active learning to teach college science courses. While this terminology is becoming increasingly common within the science education community, we were unsure how familiar DRC directors would be with active learning. Given the increasing push for the adoption of active learning in college science courses, it is encouraging that $100 \%$ of the DRC directors we interviewed were aware of active-learning practices in the classroom, though three directors (8\%) were not familiar with the specific term "active learning." The three directors who were not familiar with the term were simply unaware of the terminology but were able to deduce what the term means through their previous experiences with students and instructors. We asked DRC directors to define active learning, and they often defined active learning as a "student-centered" approach to teaching, engaging students within the classroom in something other than lecture, and described common active-learning practices, such as small group work and clicker questions. All directors confirmed that, based on their experiences interacting with science students, at least one of the science instructors at their institutions had incorporated at least one active-learning practice (e.g., used group work, clicker questions, whole-class discussion) in their courses.
When DRC directors were asked whether they were aware of any challenges that active learning posed for students with disabilities, every director was able to recall at least one instance in which active learning presented a challenge for a student with a disability in a college science course. We followed that question by asking DRC directors whether they had specifically encountered students with disabilities who had reported experiencing challenges related to five common aspects of active learning: 1) small-group work: working with a small number of students on a particular task such as a worksheet; 2) clicker questions: when students use clickers or personal response tools to answer questions that instructors pose to the whole class, usually by posting the question on a PowerPoint slide; 3) cold call or random call: instructors call on students who do not volunteer to answer a question in front of the whole class; 4) required participation or providing course points in exchange for engaging in in-class activities; and 5) online activities or activities such as online videos, quizzes, or homework assignments that students engage in for points.

Throughout the interviews, DRC directors highlighted specific examples of how these aspects of active learning could present challenges for students with six distinct types of disabilities: 1) learning disabilities (e.g., autism, dyslexia), 2) mental health/ psychological disabilities (e.g., anxiety, depression), 3) physical disabilities (e.g., cerebral palsy, spina bifida), 4) chronic health conditions (cancer, diabetes), 5) vision loss (e.g., blind), and 6) hearing loss (e.g., deaf). We acknowledge that the experiences of individuals are distinct and that the experiences of one person cannot be generalized to everyone with the same disability, nor can the experiences of individuals with a specific disability be generalized to the experiences of individuals with other disabilities. However, in this essay, we have chosen to group disabilities into categories based on the type of disability (e.g., physical disability, mental health and psychological disability). We recognize that there is debate about whether disabilities such as autism and attention-deficit/hyperactivity disorder (ADHD) are considered learning disabilities (Mayes et al., 2000; Budd et al., 2016); however, we have chosen to categorize these disabilities as learning disabilities here, because we hypothesize that students with autism and ADHD experience academic challenges that are more similar to those of students with other learning disabilities compared with students with mental health and psychological disabilities in active-learning classrooms. This organizational structure of grouping disabilities allows us to identify within-group and between-group similarities and differences.

In total, DRC directors from the 37 institutions highlighted 238 specific instances in which students with disabilities with whom they met with at their DRCs struggled with a particular aspect of active learning in their college science courses. In Table 1, we present the director-reported struggles that students with different types of disabilities encountered with each aspect of active learning. We also highlight the percentage of DRC directors who reported each challenge to show how prevalent some challenges are across institutions. In the following sections, we summarize the unique ways in which engaging in certain aspects of active learning may be difficult for students with disabilities. We want to emphasize that these experiences may not be true of all students with a particular type of disability and that these challenges were reported by DRC directors, not by students with disabilities. 

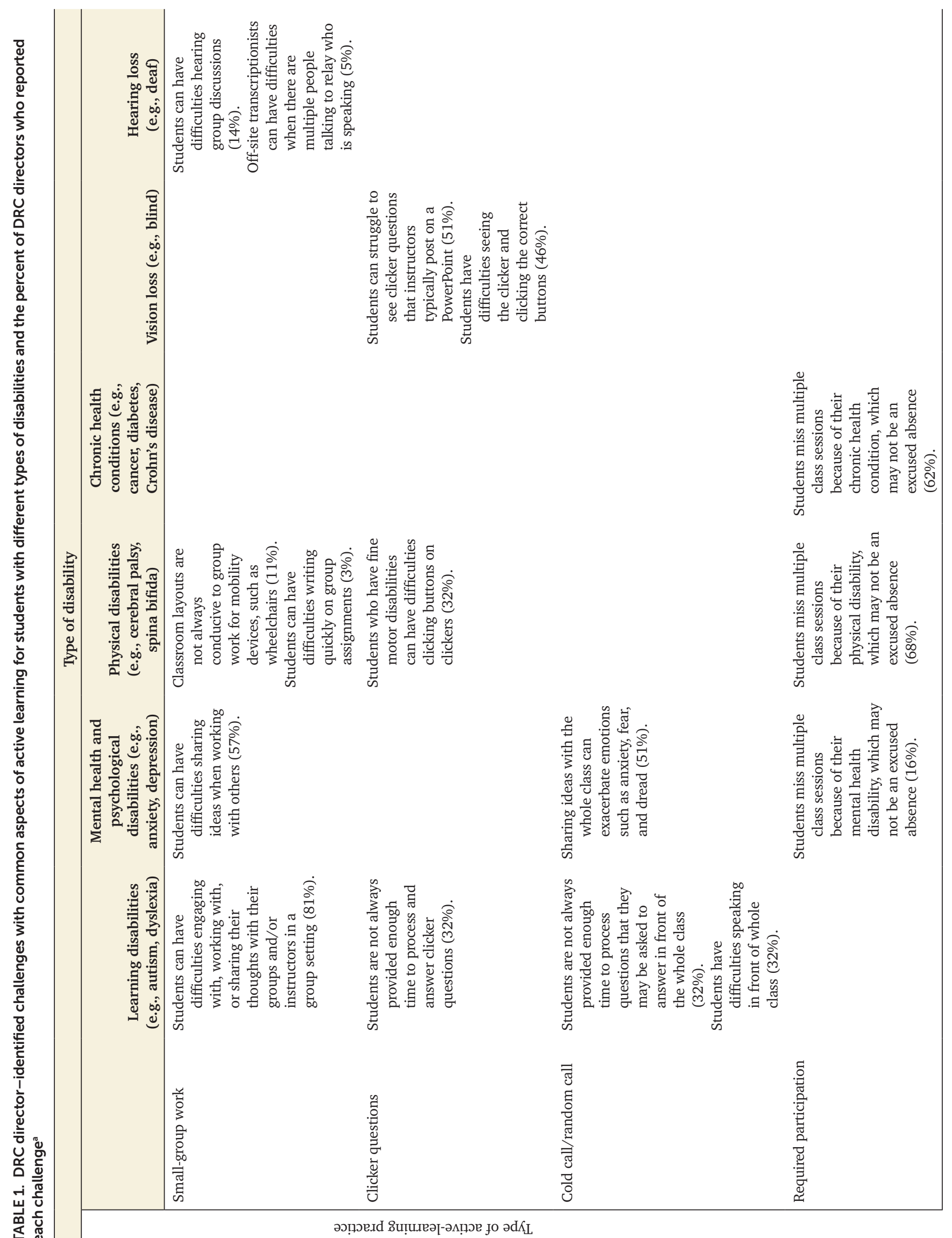


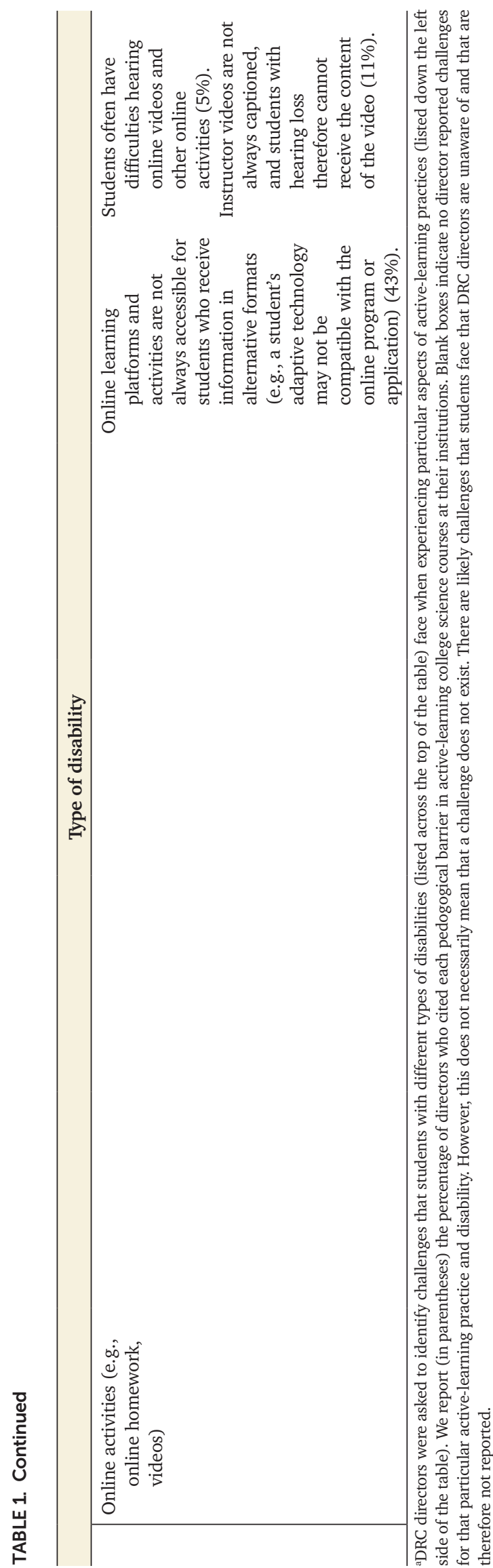

Small-Group Work. DRC directors reported that students with different types of disabilities struggle with the nature of smallgroup work. In particular, directors reported that students with both learning disabilities and students with mental health/psychological disabilities tend to have a difficult time engaging with their small groups and sharing their ideas with one another. Some directors mentioned that these interactions can lead to students being worried about being judged. DRC directors also reported that some students have a difficult time with group work based on the physical space setup. For example, some directors described group work in traditional auditorium-style lecture halls being difficult for students who use wheelchairs or other mobility devices, especially if the spaces were designed without the intention of facilitating group work. Directors also discussed how some students who are deaf or hard of hearing can have a difficult time hearing group discussions, particularly in large lecture halls, and that it is often difficult for transcription services to operate within a small group to relay the discussion.

Clicker Questions. DRC directors described that clicker questions can be challenging for students with disabilities because of how questions are posed to students and because of the process for providing an answer to the question. Specifically, DRC directors described that students with learning disabilities were not always provided with enough time to process the question and subsequently struggled to choose the correct answer. Additionally, when instructors pose questions on a slide, DRC directors explained that it was sometimes difficult for students with vision loss to either see the questions or see the buttons on the clickers required to respond to the questions. Further, DRC directors highlighted that students with other fine motor disabilities sometimes struggled to physically select or press their intended answer on the device. The stress of not being able to adequately answer a question because of a disability can increase a student's cognitive load, or the amount of information they can hold in their working memory, which could further affect the speed at which they are able to answer (Heimberg et al., 2010; Greer et al., 2013). For example, if a student is stressed about possibly hitting the wrong button on the clicker, the student may have lower mental capacity to engage in the actual question than a student who does not share such concerns.

Cold Call/Random Call. Regarding cold call and random call, most director concerns were centered around the timed and evaluative nature of these active-learning practices (Cooper et al., 2018b; Downing et al., 2020). Similar to clicker questions, directors reported that students with learning disabilities often are unable to process the cold-call question given the time constraints. Some directors described that putting students "on the spot" can be especially problematic for students who may need more time to process information. These students can also struggle with reporting out their answer to the class as a whole, due to feeling as though they did not have enough time to formulate a response. For example, students with ADHD may have difficulty focusing during class, and when asked to share out, may not be prepared to share an answer. Similarly, DRC directors described that cold call and random call were also challenging for students with mental health and psychological disabilities, especially social anxiety, when students were asked 
to share their ideas with the whole class. DRC directors highlighted that these students can feel uncomfortable or overwhelmed speaking publicly in front of their peers and instructors. This echoes the findings of previous studies on students with anxiety in active learning (Cooper et al., 2018b; Downing et al., 2020).

Required Participation. Many DRC directors described the challenge of students missing class due to their disabilities. DRC directors explained that, for many active-learning classes, attendance is often required in order to receive attendance points, participation points, or credit that is tied to in-class assignments. In other cases, it is necessary to work with classmates on projects that span multiple class periods, such as case studies. Often, students' grades are dependent on all students contributing in their group. DRC directors highlighted that these practices can be particularly challenging for students with mental health/ psychological disabilities, physical disabilities, and chronic illnesses that may result in the student missing multiple class periods. In many traditional lecture courses there is no penalty for missing class but in active-learning courses, students are often penalized by missing points and may face social repercussions if they let down group mates on in-class or out-of-class projects. Notably, students in their groups may not know about students' disabilities; if their peers were aware of this information then it could help them understand the absences. However, if the student with the disability is uncomfortable sharing this information (Cooper et al., 2020), this can create problems if students are rating one another on their participation.

Online Activities. Active-learning courses often have a significant amount of work to be completed outside class, such as watching videos in preparation for class and completing online homework (Tucker, 2012; Cooper et al., 2018a). As instructors are flipping their classes using more technology, directors described that these online homework platforms (e.g., Mastering Biology) and other learning management systems (e.g., Blackboard) can be particularly challenging for students with disabilities due to the inaccessibility of these programs and applications. This is particularly concerning for students with vision loss or for deaf and hard of hearing students who may not have access to the content in the format they need. For example, if a student with vision loss has online homework that includes models and 3D structures, they will likely have trouble completing the online homework assignment. Online content is sometimes inaccessible, because the instructor may not provide or does not have the university resources to provide appropriate accommodations, such as closed-captioning. Even if there are university resources available, it often takes time for content to be closed-captioned, and this is not helpful for instructors who may procrastinate on posting an assignment. However, resources may also be inaccessible because third-party providers of the online platform have not made their content inclusive (e.g., by not providing closed-captioning on videos) or because an adaptive technology used by a student is not compatible with the online program or application. For example, a student who uses a screen reader (a software program that creates audio or braille displays of text on the screen) may not work for particular homework programs or assignments using a specific third-party provider.
What Accommodations, If Any, Do DRC Directors Perceive Are Currently Being Provided for Students with Disabilities in Active-Learning Science Classrooms?

Given the challenges that active learning poses for students with disabilities, documenting what active learning-related accommodations are being offered to students is a key step in promoting inclusive college science classrooms for students with disabilities. Given the role of DRCs in helping instructors provide accommodations, directors would know what the general recommendations would be and if there are any specific policies.

Proactive vs. Retroactive Accommodations. Students with disabilities can either seek classroom accommodations proactively, before the course begins, or retroactively, after they have attended the course and engaged in active learning. For students with disabilities who know to seek accommodations, the general process for receiving accommodations for a traditional lecture course is relatively similar across institutions (Figure 1). First, the student approaches the DRC and self-discloses that they have a disability and provides documentation. ${ }^{3}$ After the documentation is approved, the student meets with a coordinator to discuss his or her needs and to identify potential challenges in upcoming courses. Based on this conversation, the DRC coordinator and the student agree on proactive accommodations or accommodations that are identified to proactively alleviate potential challenges for the student in upcoming courses. However, according to DRC directors, if a student is enrolled in an active-learning course, they often experiences challenges that are not accounted for in the initial meeting with the coordinator due to unique aspects of active learning. As such, the student must return to the DRC or initiate a conversation with the instructor after experiencing a challenge with active learning to discuss the challenge and brainstorm retroactive accommodations, or accommodations to alleviate challenges that students have already experienced in their courses (Figure 1).

The challenge of providing accommodations retroactively is that it takes additional time and meetings to ensure that the student is provided with the accommodations necessary to be successful in a course. The additional steps that it takes for students to receive appropriate accommodations can lead to students feeling frustrated, and they may be less likely to complete the process of securing an accommodation (Hong, 2015). Proactive measures can potentially reduce the amount of time it takes for the DRC, the instructor, and the student to accommodate the student's specific needs in active-learning courses. Further, encountering challenges (such as many of the challenges we

\footnotetext{
${ }^{3}$ Directors described that documentation is required in most instances in order to receive accommodations. Examples of documentation often include official diagnoses from healthcare providers, psychoeducational evaluations, and individualized education plans from high school that describe how the student's disability impacts him or her academically. A few directors described that, for some apparent or visible disabilities (e.g., a student in a wheelchair), official documentation is not necessarily required but is up to the discretion of the coordinator. Because obtaining documentation can often take time, some directors discussed implementing provisional accommodations until official documentation is received. Others discussed grants and other opportunities to financially assist students in obtaining appropriate documentation, particularly for students without health insurance.
} 


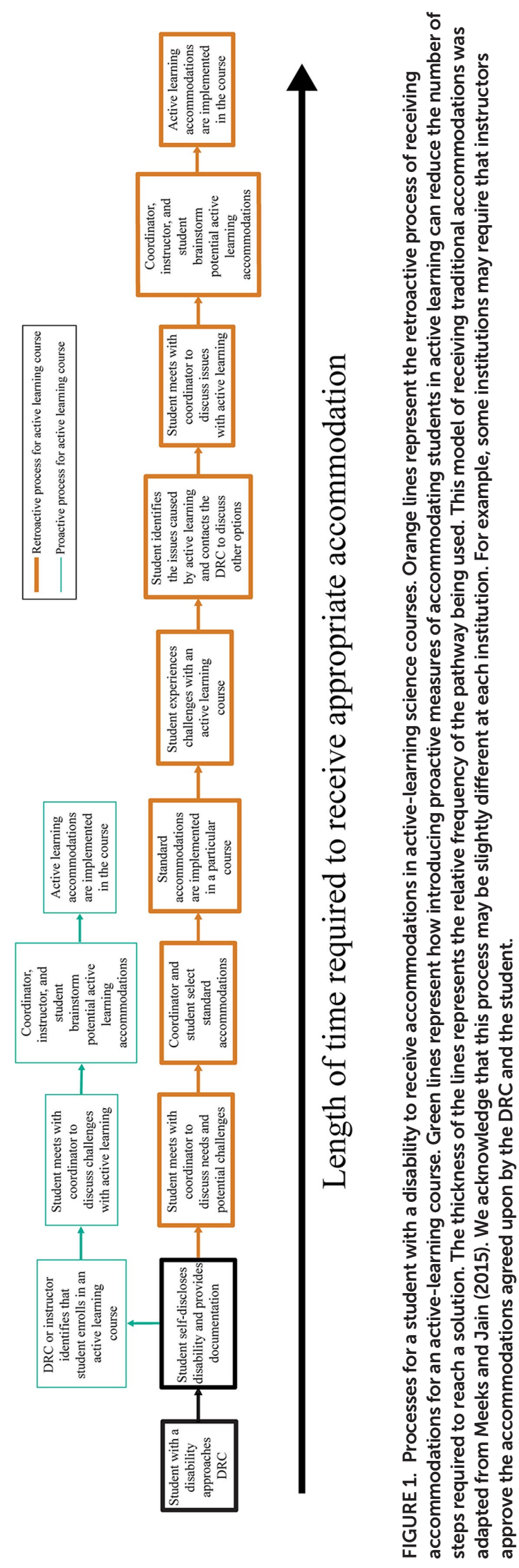

describe in Table 1) may be embarrassing, frustrating, and upsetting for students and may result in lost course points. Proactive accommodations can benefit students by protecting them from experiencing these issues in the first place.

The current state of proactive and retroactive accommodations for active learning in college science courses: Despite all DRC directors being familiar with active learning-related challenges for students with disabilities, the majority of active learningrelated accommodations are provided to students retroactively, meaning that students only identify that they need an accommodation once they have attended an active-learning course. Only $16 \%$ of DRC directors were able to highlight an example of their DRC providing a student with a proactive accommodation for an active-learning course. In these cases, an individual within the DRC knew of an active-learning science course, discussed active learning and the possible challenges with the student before the student started the course, and organized necessary proactive accommodations before the course began. Importantly, no DRC directors discussed systematic ways of proactively providing active-learning accommodations for every student. That is, no DRC director we interviewed had any systematic process in place for their institution that proactively identified active-learning courses for students so that they could discuss accommodations before attending the first class. This could mean that, due to the lack of processes and procedures in place, students with disabilities enter science active-learning courses unaware of the challenges they may face and may discover additional challenges late in the term as instructors introduce active-learning techniques that may be new to the student. In these cases, students with disabilities may need to advocate for themselves in order to retroactively seek accommodations, something that could have been prevented had more systematic procedures been in place.

Standardized vs. Individualized Accommodations. DRCs are designed to offer students an array of accommodations to meet their needs. Many students encounter a standard set of challenges, and standardized accommodations have been developed. These standardized accommodations, such as note-taking and extended test time, are commonly employed accommodations that are meant to improve the learning experiences of students with disabilities. However, at times, the standardized accommodations are insufficient to meet a student's needs. In these cases, individualized accommodations are made when a student, DRC, and an instructor determine a unique accommodation for the student.

Legal mandates and best practices for disability services call for an individualized approach to accommodating students (Cory, 2011; Meeks and Jain, 2015). Individualized accommodations allow for each individual to be treated uniquely and are tailored to a student's specific needs. Indeed, many of the DRC directors we talked to highlighted how they consider student needs and accommodations on a case-by-case basis and engage students in an interactive process of finding the appropriate accommodations. Directors also stated that it is not best practice to assume that two students with the same disability would necessitate the same accommodation for the same pedagogical practice in the same course, which is consistent with prior literature (Cory, 2011; Shaw and Dukes, 2001). However, the reality of the sheer number of students using the DRC at 
large-enrollment institutions means that many DRCs do have a set of standardized accommodations that they draw from when deciding how to accommodate students in traditional courses, including extended time for exams, reduced distraction testing environments, note-taking services, and interpreters. Importantly, many of the active learning-related challenges that DRC directors highlighted (Table 1) cannot be alleviated by using a standard accommodation. For example, a note-taker may be useful to a student in a traditional lecture but may struggle to accurately capture the thoughts generated in a small-group discussion. Further, the note-taker would need to be in the same group as all of the students who need this accommodation, which would be logistically challenging in a large class. As such, it is likely that most active-learning accommodations need to be individualized accommodations.

The current state of standardized and individualized accommodations in active learning: We were interested in whether any of the DRCs had developed standardized accommodations for active learning, or a suite of accommodations that can alleviate common challenges experienced by students with disabilities. We found that none of the 37 DRCs had standardized accommodations for active learning. DRCs exclusively developed individualized solutions for students on a case-by-case basis. In fact, all DRCs had provided students with an individualized accommodation for active learning at least once, with a total of 141 accommodations reported by directors. This is important, because it shows that DRCs can accommodate students with disabilities in active-learning courses. However, compared with standardized accommodations, individualized accommodations often take more time, resources, and effort from the DRC, instructor, and student. In Table 2, we highlight accommodations specific to active-learning practices that DRC directors described implementing for students with disabilities. Interestingly, none of the institutions described using these accommodations regularly. However, looking across institutions, we identified several accommodations that were implemented across multiple DRCs. In the following sections, we summarize some of the most frequently used accommodations across institutions.

Accommodations for Small-Group Work. DRC directors most frequently mentioned examples of providing accommodations for small-group work. Some of the example accommodations involve ensuring constructive group dynamics for students, such as allowing students to choose their own groups, instructors predetermining groups for students, and reducing group sizes or allowing students to work in partner pairs. This could mean that some students are assigned to the same seats and groups for the entire semester, which allows students to get to know their group mates and become comfortable working together. For students who may have a difficult time interacting with group members face-to-face or who may be unable to attend class, directors facilitated students meeting with their groups virtually, using an online platform such as Zoom, where students could even interact with one another without their video turned on. Regarding constraints on the physical space of the classroom, DRC directors suggested, when possible, ensuring that the room had accessible tables, chairs, and furniture to facilitate smallgroup work. However, given that many of these classroom spaces were not designed with group work and accessibility needs in mind, one director described requesting the instructor change the workplace setting to allow students to meet in the hallway or outside the classroom. In cases in which no other alternatives could be reached, some directors described allowing students to work alone or to complete an alternative assignment instead of working with their groups.

Accommodations for Clicker Questions. With regard to the use of clicker questions in the classroom, directors described giving access to questions before class for students who may need more time to process the questions or having them complete the questions before or after class. This could be done by having the instructor post the slides and questions to the course learning management system or by requesting that the student visit the instructor's office before or after class to receive the necessary materials. Other accommodations included providing students with more time to respond to the question by having the instructor read the question aloud before starting the timer or allowing a student who may need additional time to motion to the instructor after they have enough time to read the question. Additionally, DRC directors mentioned using classroom aides or volunteers to assist a student (e.g., a student with fine motor disabilities) in physically using the clicker. This individual could be someone who is hired by the university's DRC or it could be another student volunteer in the class. Further, DRC directors recommended ensuring that the clicker meets accessibility standards. For example, this could include making sure that the buttons are large enough for the student to press or that the buttons are labeled in braille for a student with vision loss. Some directors have had instructors implement clicker systems that use mobile apps or computer programs, because these systems can be better for students if they are compatible with their existing adaptive technology (e.g., adaptive smartphones). Other directors mentioned that it is helpful if departments and universities use the same polling platform across courses for consistency for students who may receive clicker accommodations.

Accommodations for Cold Call/Random Call. DRC directors described several ways in which students can be accommodated when instructors use cold call and random call. These accommodations typically involve an agreement between the student and instructor about how, if at all, the student wishes to be called on. For example, instructors can notify students before they will be called on, so the students have advanced notice to prepare. Alternatively, instructors can structure the class so that students discuss with their partners or groups before speaking out in front of the whole class to ensure that they have had time to prepare their answers and can speak on behalf of their groups. In other instances, directors described students only being called on if their hands are raised or being able to opt out or pass if called on. As an alternative to speaking out in front of class at all, some directors described not having particular students be called on, and instead having students submit their answers through a written form.

Accommodations for Required Participation. Nearly all directors who discussed issues with required participation also described the use of a flexible attendance and participation form that is agreed upon by both the student and instructor. While missing class is often detrimental in active-learning 





courses, this agreement form ensures that there are clear expectations from both the student and instructor regarding participation in terms of the number of classes that can be missed or what constitutes adequate participation in the course. Some directors discussed situations in which students attend class virtually by using Skype or Zoom to "attend" class from the hospital, home, or wherever they may be.

Accommodations for Online Activities. Several DRC directors mentioned that instructors worked with DRC staff and other university personnel, such as instructional designers, to ensure that videos are captioned and that tactile graphics or braille can be added to interpret online images or models. If an instructor does not know how to do this, many of the DRC directors mentioned having individuals in their offices who can help. This often takes time, so DRC directors suggested reaching out to their offices as soon as possible when instructors are considering implementing new technologies in their courses. There are other existing assistive technologies that can help students navigate their online activities, such as screen readers. However, DRC directors recommended that instructors ensure that the online activities and software they choose have accessibility features and work with most assistive devices that students may already be using. DRCs may be able to point instructors to common software companies used in their discipline that are most accessible to students. In cases in which students may have issues, directors said that either they or instructors notify software companies if and when their products are inaccessible to student users.

\section{What Steps Can DRC Directors and Instructors Take to Enhance the Experiences of Students with Disabilities in Active-Learning Science Courses?}

We drew from the current literature and our conversations with DRC directors to develop a list of four suggestions for DRC staff and science instructors who are looking to create more inclusive active-learning environments for students with disabilities.

Students May Benefit from Instructors Being Transparent about Whether They Teach in an Active-learning Way and What Specific Active-learning Practices They Tend to Use. To better accommodate students with disabilities in active-learning classrooms, DRCs need to know which science courses are taught in active-learning ways and what practices instructors tend to use so that they can proactively identify solutions for students with disabilities who are enrolled in the courses before students start a class. Many DRC directors recommended that instructors provide both the DRC and the students information about how their science courses will be taught. Being explicit whether one teaches in an active-learning way and what active-learning practices are used in a course (e.g., small-group work, clicker questions) in the syllabus and course directory could be helpful for DRCs and students working to identify proactive accommodations before the class begins. We encourage DRC directors to consider a systemic collection of course syllabi or to survey instructors yearly about which courses are taught using specific active-learning practices. If this process is too time-intensive for the DRC staff, the onus could be placed on instructors by having them voluntarily send their syllabi or course descriptions to the DRC to convey which active-learning practices are used in the class. Having access to this information about active-learning practices would allow DRCs to engage students in the accommodation process proactively.

\section{Students May Benefit when Instructors Proactively Design} Their Courses to Be Inclusive of Students with Disabilities. DRC directors suggested that instructors design their courses to be inclusive of students with disabilities and urged universities to find ways in which they can provide instructors with the necessary resources and support to make their classrooms more inclusive. Specifically, directors suggested that instructors could incorporate elements of universal design for learning (UDL; Rose and Meyer, 2002), which is a consistent recommendation among other studies of disability services staff (Kalivoda and Totty, 2004; Burgstahler and Moore, 2009; Florida College System, 2009). UDL is a framework, derived from architecture, that attempts to design accessible learning environments and curricula to accommodate all learners without specialized adaptation or accommodation (Rose and Meyer, 2002; Burgstahler and Cory, 2008). Common examples of implementing UDL in college science courses could include ensuring that all videos are closed-captioned, text sources are compatible with screen readers, and additional time is provided for assessments and activities for all students (e.g., giving all students 10 minutes to take a quiz that may only take 5 minutes for most students). Several directors also mentioned that they have personnel on staff who are trained in UDL principles and are willing to help instructors implement UDL in their courses. The use of UDL principles in college science courses could create a more inclusive environment for all students, including students with disabilities.

When Proactive Accommodations Are Not Possible, DRCs and Instructors Can Support Students with Disabilities as They Navigate the Retroactive Process in Seeking Accommodations. Research has shown that individuals with disabilities can experience difficulties with self-advocacy and may specifically struggle with revealing to instructors their need for accommodations (Lynch and Gussel, 1996; Brinkerhoff et al., 2002; Hong, 2015). For many students, college is the first time that they are solely responsible for advocating for their disability-related needs (Eckes and Ochoa, 2005; Ochoa, 2007); as such, DRC directors described supporting students by coaching them about how to talk with their instructors about their disabilities and their need for accommodation.

Instructors can support students by making an announcement on the first day of class or on their syllabi that invites individuals with disabilities to approach them if they encounter a challenge in their classrooms. Further, instructors can express their willingness to work with students with disabilities to provide appropriate accommodations and can provide students with information about an institution's DRC. Additionally, instructors can survey students about their identities (e.g., gender, college-generation status, commute time to campus) to get a sense of who is in the class and the challenges they may encounter. As part of this survey, instructors could ask about disability status (see Supplemental Material for an example survey question). This would allow instructors to reach out to students who respond to this question to discuss proactive 
accommodations based on the specific active-learning exercises used in the course. The survey question uses the same categories of disabilities presented in this paper and could be used in future research to continue to uncover unique challenges and accommodations in active-learning science courses from the perspectives of students with specific disabilities.

Standardize Active-Learning Accommodations. While there was no standardized set of accommodations that instructors could turn to when trying to accommodate a student in an active-learning class, we noted that many of the accommodations that were developed for students were the same across institutions. However, there were also accommodations that were only used by one or two institutions. As such, sharing information about what individualized accommodations have been developed for students with disabilities in active-learning classrooms may save time and effort for DRCs. It is also possible that students at different institutions experience similar challenges and thus one institution may have potential solutions that another could benefit from. Overall, we lobby for increased crosstalk among DRCs about active learning through organizations such as the Association of Higher Education and Disability and hypothesize that sharing information about developed accommodations could benefit both DRCs and students.

\section{TAKEAWAYS}

As college science classrooms are increasingly adopting active-learning practices, it is imperative that the science education community consider what challenges active learning may pose for students with disabilities, how stakeholders are working together to alleviate such challenges, and what is working with regard to making active learning more inclusive for students with disabilities. We advocate that a multipronged approach is needed: examining these questions through the lenses of students with disabilities, science instructors who teach in active-learning ways, and DRC directors who implement accommodations across college campuses.

As a first step, we probed the perspectives of DRC directors. Through interviews with 37 DRC directors, we have begun to identify an array of challenges that active learning may pose for students with disabilities in college science. However, there are accommodations available that can be used to lessen such challenges, although there seem to be no standardized accommodations for students with disabilities in active-learning classes, and the majority of accommodations are put in place retroactively, after students have begun their course work. Additionally, these interviews revealed key ways in which DRCs and instructors can make active-learning science classes more inclusive: by being transparent and upfront about which active-learning practices are incorporated into specific science classes, by proactively designing courses to be inclusive of students with disabilities, by helping students navigate retroactive accommodations when proactive accommodations are not possible, and by standardizing active-learning accommodations.

While this essay was focused on active learning, we argue that we can use the guiding questions that we present in this essay to examine how inclusive other science learning environments are for students with disabilities, including undergraduate research experiences, lab courses, or traditional lecture courses. If we truly want to move toward creating a more diverse scientific community, then it is imperative that we, as education researchers and instructors, devote more time and effort to understanding the experiences of undergraduates with disabilities in science. If we do not make a substantial effort to be more inclusive of these individuals, and do not move swiftly to accommodate students as we transition our science classrooms from traditional lecture to active learning, then we may be losing out on retaining some of the best and brightest minds in science.

\section{POSITIONALITY}

One author of this essay has a physical disability and has previously used DRC accommodations as an undergraduate and graduate student (L.E.G.). Additionally, all authors on this essay are proponents of active learning and have taught biology classes using active learning. We are all working to make our own active-learning teaching more inclusive for students with disabilities and recognize that this is a very difficult, yet important, action to take.

\section{ACKNOWLEDGMENTS}

We are extremely grateful to the 37 directors who shared their thoughts, experiences, and expertise working with students with disabilities. We also thank Tiffany Bailey and the ASU Biology Education Research Laboratory for their insights and feedback on an earlier draft of this essay. L.E.G. was supported by an NSF Graduate Fellowship (DGE-1311230), and F.G. was supported by a Howard Hughes Medical Institute Inclusive Excellence grant (no. 11046). Any opinions, findings, conclusions, or recommendations expressed in this material are those of the authors and do not necessarily reflect the views of the NSF or HHMI. The data collection was approved by Arizona State University's Institutional Review Board STUDY00007435.

\section{REFERENCES}

Americans with Disabilities Act of 1990, Pub. L. No. 101-336, 104 Stat. 328 (ADA). (1990). Retrieved March 1, 2020, from https://www.ada.gov/pubs/ adastatute08.htm

ADA Amendments Act of 2008, Pub. L. No. 110-325, Stat. 3406. (2008) Retrieved March 1, 2020, from https://www.ada.gov/pubs/adastatute08 htm

American Association for the Advancement of Science. (2011). Vision and change in undergraduate biology education: A call to action. Washington, DC.

American Psychological Association. (2020). Publication manual of the American Psychological Association (7th ed.). Washington, DC

Ballen, C. J., Aguillon, S. M., Awwad, A., Bjune, A. E., Challou, D., Drake, A. G., \& Goldberg, E. E. (2019). Smaller classes promote equitable student participation in STEM. BioScience, 69(8), 669-680

Ballen, C. J., Wieman, C., Salehi, S., Searle, J. B., \& Zamudio, K. R. (2017). Enhancing diversity in undergraduate science: Self-efficacy drives performance gains with active learning. CBE-Life Sciences Education, 16(4), $\operatorname{ar} 56$.

Birks, M., \& Mills, J. (2015). Grounded theory: A practical guide. Thousand Oaks, CA: Sage.

Bonwell, C. C., \& Eison, J. A. (1991). Active learning: Creating excitement in the classroom (1991 ASHE-ERIC Higher Education Reports). Retrieved from ERIC (ED336049).

Braun, D. C., Clark, M. D., Marchut, A. E., Solomon, C. M., Majocha, M., Davenport, Z., ... \& Gormally, C. (2018). Welcoming Deaf students into STEM: Recommendations for university science education. CBE-Life Sciences Education, 17(3), es10. 
Brinkerhoff, L. C., McGuire, J. M., \& Shaw, S. F. (2002). Postsecondary education and transition for students with learning disabilities. Austin, TX: Pro-Ed. Retrieved from ERIC (ED463620)

Budd, J., Fichten, C. S., Jorgensen, M., Havel, A., \& Flanagan, T. (2016). Postsecondary students with specific learning disabilities and with attention deficit hyperactivity disorder should not be considered as a unified group for research or practice. Journal of Education and Training Studies, 4(4), 206-216.

Burgstahler, S. E., \& Cory, R. C. (Eds.) (2008). Universal design in higher education. Universal Design in Higher Education: From Principles to Practice. Cambridge, MA: Harvard Education Press.

Burgstahler, S., \& Moore, E. (2009). Making student services welcoming and accessible through accommodations and universal design. Journal of Postsecondary Education and Disability, 21(3), 155-174.

Cooper, K. M., \& Brownell, S. E. (2016). Coming out in class: Challenges and benefits of active learning in a biology classroom for LGBTQIA students. CBE-Life Sciences Education, 15(3), ar37

Cooper, K. M., Ding, L., Stephens, M. D., Chi, M. T., \& Brownell, S. E. (2018a). A course-embedded comparison of instructor-generated videos of either an instructor alone or an instructor and a student. CBE-Life Sciences Education, 17(2), ar31.

Cooper, K. M., Downing, V. R., \& Brownell, S. E. (2018b). The influence of active learning practices on student anxiety in large-enrollment college science classrooms. International Journal of STEM Education, 5(1), 23.

Cooper, K. M., Gin, L. E., \& Brownell, S. E. (2020). Depression as a concealable stigmatized identity: What influences whether students conceal or reveal their depression in undergraduate research experiences? International Journal of STEM Education, 7(1), 1-18.

Cory, R. C. (2011). Disability services offices for students with disabilities: A campus resource. New Directions for Higher Education, 154(154), 27-36

Creswell, J. W. (1994). Research design: Qualitative and quantitative approach. Thousand Oaks, CA: SAGE Publications.

Dewsbury, B., \& Brame, C. J. (2019). Inclusive teaching. CBE-Life Sciences Education, 18(2), fe2.

Downing, V. R., Cooper, K. M., Cala, J. M., Gin, L. E., \& Brownell, S. E. (2020). Fear of negative evaluation and student anxiety in community college active learning science courses. CBE-Life Sciences Education, 19(2), ar20.

Dowrick, P. W., Anderson, J., Heyer, K., \& Acosta, J. (2005). Postsecondary education across the USA: Experiences of adults with disabilities. Journal of Vocational Rehabilitation, 22(1), 41-47.

Dunn, C., Rabren, K. S., Taylor, S. L., \& Dotson, C. K. (2012). Assisting students with high-incidence disabilities to pursue careers in science, technology, engineering, and mathematics. Intervention in School and Clinic, 48(1), 47-54.

Eckes, S. E., \& Ochoa, T. A. (2005). Students with disabilities: Transitioning from high school to higher education. American Secondary Education, 33(3), 6-20

Eddy, S. L., \& Brownell, S. E. (2016). Beneath the numbers: A review of gender disparities in undergraduate education across science, technology, engineering, and math disciplines. Physical Review Physics Education Research, 12(2), 020106

Eddy, S. L., Brownell, S. E., Thummaphan, P., Lan, M.-C., \& Wenderoth, M. P. (2015). Caution, student experience may vary: Social identities impact a student's experience in peer discussions. CBE-Life Sciences Education, 14(4), ar45.

Eddy, S. L., \& Hogan, K. A. (2014). Getting under the hood: How and for whom does increasing course structure work? CBE-Life Sciences Education, 13(3), 453-468.

England, B. J., Brigati, J. R., \& Schussler, E. E. (2017). Student anxiety in introductory biology classrooms: Perceptions about active learning and persistence in the major. PLOS ONE, 12(8) e0182506. https://doi.org/10.1371/ journal.pone.0182506

England, B. J., Brigati, J. R., Schussler, E. E., \& Chen, M. M. (2019). Student anxiety and perception of difficulty impact performance and persistence in introductory biology courses. CBE-Life Sciences Education, 18(2), $\operatorname{ar} 21$.

Erickson, W., Lee, C., \& von Schrader, S. (2017). Disability statistics from the American Community Survey. Ithaca, NY: Cornell University Yang-Tan Institute. Retrieved March 1, 2020, from www. disabilitystatistics.org
Feldblum, C. R. (1996). The (R) evolution of physical disability anti-discrimination law: 1976-1996. Mental and Physical Disability Law Reporter, 20(5), 613-621.

Fine, M., \& Asch, A. (1988). Disability beyond stigma: Social interaction, discrimination, and activism. Journal of Social Issues, 44(1), 3-21.

Florida College System. (2009). Program review disability services. Tallahassee: Florida College System.

Freeman, S., Eddy, S. L., McDonough, M., Smith, M. K., Okoroafor, N., Jordt, H., \& Wenderoth, M. P. (2014). Active learning increases student performance in science, engineering, and mathematics. Proceedings of the National Academy of Sciences USA, 111(23), 8410-8415.

Getzel, E. E., \& Thoma, C. A. (2008). Experiences of college students with disabilities and the importance of self-determination in higher education settings. Career Development for Exceptional Individuals, 31(2), 77-84.

Gonzales, F. (2016). For some, active learning can be a nightmare. Tomorrow's Teaching and Learning. Retrieved March 1, 2020, from https://tomprof stanford.edu/posting/1550.

Greer, D. L., Crutchfield, S. A., \& Woods, K. L. (2013). Cognitive theory of multimedia learning, instructional design principles, and students with learning disabilities in computer-based and online learning environments. Journal of Education, 193(2), 41-50.

Haak, D. C., HilleRisLambers, J., Pitre, E., \& Freeman, S. (2011). Increased structure and active learning reduce the achievement gap in introductory biology. Science, 332(6034), 1213-1216.

Hadley, E. C. (2007). Testing interventions to preserve walking ability: Progress against disability, one step at a time. The Journals of Gerontology Series A: Biological Sciences and Medical Sciences, 62(8), 834-836.

Hall, M. (2017). Does active learning disadvantage the learning disabled? Innovative Instructor. Retrieved March 1, 2020, from https://ii.library.jhu.edu/ 2017/03/17/does-active-learning-disadvantage-the-learning-disabled

Heimberg, R. G., Brozovich, F. A., \& Rapee, R. M. (2010). A cognitive behavioral model of social anxiety disorder: Update and extension. In Social anxiety (pp. 395-422). Amsterdam, Netherlands: Elsevier.

Hong, B. S. (2015). Qualitative analysis of the barriers college students with disabilities experience in higher education. Journal of College Student Development, 56(3), 209-226.

Janiga, S. J., \& Costenbader, V. (2002). The transition from high school to postsecondary education for students with learning disabilities: A survey of college service coordinators. Journal of Learning Disabilities, 35(5), 463-470.

Jenson, R. J., Petri, A. N., Day, A. D., Truman, K. Z., \& Duffy, K. (2011). Perceptions of self-efficacy among STEM students with disabilities. Journal of Postsecondary Education and Disability, 24(4), 269-283.

Johnson, A. L. (2006). Students with disabilities in postsecondary education: Barriers to success and implication to professionals. Vistas Online, 1(1), 1-16. Retrieved March 1, 2020, from https://www.counseling.org/ Resources/Library/VISTAS/vistas06_online-only/Johnson.pdf

Kalivoda, K. S., \& Totty, M. C. (2004). Disability services as a resource: Advancing Universal Design. Implementing Universal Design in Higher Education, 1(1), 267-277. https://www.researchgate.net/profile/David_Arendale/ publication/327668057_Arendale_D_R_Poch_R_2008_Using_Universal _Instructional_Design_for_administrative_leadership_planning_and _evaluation_In_J_I_Higbee_E_Goff_Eds_Pedagogy_and_student _services_for_institutional_transformat/links/5b9d0ffd45851574f7cc4681/ Arendale-D-R-Poch-R-2008-Using-Universal-Instructional-Design -for-administrative-leadership-planning-and-evaluation-In-J-I-Higbee -E-Goff-Eds-Pedagogy-and-student-services-for-institutional-t pdf\#page $=277$

Kenny, L., Hattersley, C., Molins, B., Buckley, C., Povey, C., \& Pellicano, E. (2016). Which terms should be used to describe autism? Perspectives from the UK autism community. Autism, 20(4), 442-462.

Kurth, N., \& Mellard, D. (2006). Student perceptions of the accommodation process in postsecondary education. Journal of Postsecondary Education and Disability, 19(1), 71-84.

Landis, J. R., \& Koch, G. G. (1977). The measurement of observer agreement for categorical data. Biometrics, 33(1), 159-174.

Lee, A. (2011). A comparison of postsecondary science, technology, engineering, and mathematics (STEM) enrollment for students with and without disabilities. Career Development for Exceptional Individuals, 34(2), 72-82. 
Love, T. S., Kreiser, N., Camargo, E., Grubbs, M. E., Kim, E. J., Burge, P. L., \& Culver, S. M. (2014). STEM faculty experiences with students with disabilities at a land grant institution. Journal of Education and Training Studies, 3(1), 27-38.

Lum, D. (2010). Culturally competent practice: A framework for understanding. Toronto, Canada: Nelson Education.

Lynch, R. T., \& Gussel, L. (1996). Disclosure and self-advocacy regarding disability-related needs: Strategies to maximize integration in postsecondary education. Journal of Counseling \& Development, 74(4), 352 357

Madaus, J. W. (1996). Administration of postsecondary offices for students with disabilities: Perceptions of essential job functions. Doctoral Dissertations, AAI9634542. https://opencommons.uconn.edu/dissertations/ AAI9634542

Madaus, J. W. (2005). Navigating the college transition maze: A guide for students with learning disabilities. Teaching Exceptional Children, 37(3), $32-37$.

Madaus, J. W. (2011). The history of disability services in higher education New Directions for Higher Education, 154(1), 5-15.

Marshak, L., Van Wieren, T., Ferrell, D. R., Swiss, L., \& Dugan, C. (2010). Exploring barriers to college student use of disability services and accommodations. Journal of Postsecondary Education and Disability, 22(3) 151-165.

Mayes, S. D., Calhoun, S. L., \& Crowell, E. W. (2000). Learning disabilities and ADHD: Overlapping spectrum disorders. Journal of Learning Disabilities, 33(5), 417-424.

Meeks, L. M., \& Jain, N. R. (2015). The guide to assisting students with disabilities: Equal access in health science and professional education. New York, NY: Springer

Meredith, S. K. (2014). Accessing disabled student services: Students' perspectives. Long Beach: California State University, Long Beach.

Moon, N. W., Todd, R. L., Morton, D. L., \& Ivey, E. (2012).Accommodating students with disabilities in science, technology, engineering, and mathematics (STEM) (pp. 8-21). Atlanta: Center for Assistive Technology and Environmental Access, Georgia Institute of Technology.

National Center on Disability and Journalism. (2018). Disability language style guide. Retrieved March 1, 2020, from https://ncdj.org/style-guide

National Center for Education Statistics. (2015). Digest of education statistics. Retrieved March 1, 2020, from https://nces.ed.gov/fastfacts/display .asp? $i d=64$

National Science Foundation. (2016). Women, minorities, and persons with disabilities in science and engineering. Alexandria, VA. Retrieved March 1 2020, from https://ncses.nsf.gov/pubs/nsf19304/data.

Ochoa, T. A. (2007). Case \#16 A special case of diversity: Students with disabilities in higher education. Unleashing Suppressed Voices on College Campuses: Diversity Issues in Higher Education, 19, 193-198.
Oliver, M. (1996). The social model in context. In Understanding disability (pp. 30-42). New York, NY: Springer.

Oliver, M. (2013). The social model of disability: Thirty years on. Disability \& Society, 28(7), 1024-1026.

Prince, M. (2004). Does active learning work? A review of the research. Journal of Engineering Education, 93(3), 223-231.

Rose, D. H., \& Meyer, A. (2002). Teaching every student in the digital age: Universal design for learning. Retrieved from ERIC (ED466086).

Ruban, L. M., McCoach, D. B., McGuire, J. M., \& Reis, S. M. (2003). The differential impact of academic self-regulatory methods on academic achievement among university students with and without learning disabilities. Journal of Learning Disabilities, 36(3), 270-286.

Rule, A. C., Stefanich, G. P., Haselhuhn, C. W., \& Peiffer, B. (2009). A Working Conference on Students with Disabilities in STEM Coursework and Careers, University of Northern lowa, ED505568.

Section 504 of the Rehabilitation Act of 1973, 34 C.F.R. Part 104. (1973) Retrieved March 1, 2020, from https://www2.ed.gov/policy/rights/reg/ ocr/edlite-34cfr104.html

Shakespeare, T. (2006). The social model of disability. Disability Studies Reader, 2, 197-204.

Shaw, S. F., \& Dukes, L. L. (2001). Program standards for disability services in higher education. Journal of Postsecondary Education and Disability, 14(2), 81-90.

Smith, S. G., English, R., \& Vasek, D. (2002). Student and parent involvement in the transition process for college freshmen with learning disabilities. College Student Journal, 36(4), 491-504.

Street, C. D., Koff, R., Fields, H., Kuehne, L., Handlin, L., Getty, M., \& Parker D. R. (2012). Expanding access to STEM for at-risk learners: A new application of universal design for instruction. Journal of Postsecondary Education and Disability, 25(4), 363-375.

Theobald, E. J., Hill, M. J., Tran, E., Agrawal, S., Arroyo, E. N., Behling, S., ... \& Freeman, S. (2020). Active learning narrows achievement gaps for underrepresented students in undergraduate science, technology, engineering, and math. Proceedings of the National Academy of Sciences USA. doi: $10.1073 /$ pnas.1916903117

Thomas, D. R. (2003). A general inductive approach for qualitative data analysis. New Zealand: University of Auckland.

Trammell, J. (2009). Postsecondary students and disability stigma: Development of the postsecondary student survey of disability-related stigma (PSSDS). Journal of Postsecondary Education and Disability, 22(2), 106-116.

Tucker, B. (2012). The flipped classroom. Education Next, 12(1), 82-83.

Vaughan, C. E. (2009). People-first language: An unholy crusade. Braille Monitor). Baltimore, MD: National Federation of the Blind, 52(3). https://www .nfb.org//images/nfb/publications/bm/bm09/bm0903/bm0903tc.htm

West, J. (1993). The evolution of disability rights. Baltimore, MD: Paul H Brookes. 